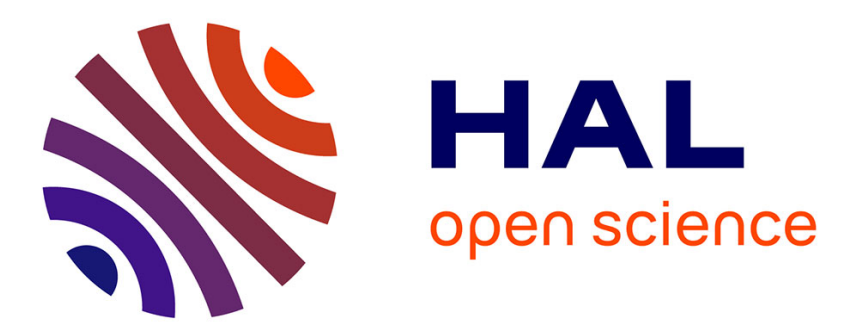

\title{
Physical exercise-related endophenotypes in anorexia nervosa
}

Laura Di Lodovico, Hanna Hatteea, Céline Couton, Philibert Duriez, Janet Treasure, Philip Gorwood

\section{- To cite this version:}

Laura Di Lodovico, Hanna Hatteea, Céline Couton, Philibert Duriez, Janet Treasure, et al.. Physical exercise-related endophenotypes in anorexia nervosa. International Journal of Eating Disorders, 2021, Online ahead of print. 10.1002/eat.23503 . inserm-03170394

\section{HAL Id: inserm-03170394 https://www.hal.inserm.fr/inserm-03170394}

Submitted on 16 Mar 2021

HAL is a multi-disciplinary open access archive for the deposit and dissemination of scientific research documents, whether they are published or not. The documents may come from teaching and research institutions in France or abroad, or from public or private research centers.
L'archive ouverte pluridisciplinaire HAL, est destinée au dépôt et à la diffusion de documents scientifiques de niveau recherche, publiés ou non, émanant des établissements d'enseignement et de recherche français ou étrangers, des laboratoires publics ou privés. 


\title{
Physical exercise-related endophenotypes in Anorexia Nervosa
}

\author{
Laura Di Lodovico $^{1 *}$, Hanna Hatteea ${ }^{1}$, Céline Couton ${ }^{2,3}$, Philibert Duriez $^{1,4}$, Janet Treasure ${ }^{5}$ \\ and Philip Gorwood ${ }^{1,4}$
}

1 Clinique des Maladies Mentales et de l'Encéphale, Hôpital Sainte-Anne, GHU Paris Psychiatrie et Neurosciences, F-75014 Paris, France

2 Université Paris-Saclay, Psychiatrie-Comorbidités-Addictions, 94804 Villejuif, France.

3 Psychiatry and addictology unit, APHP, Hôpitaux Universitaires Paris-Sud, Villejuif, France

${ }^{4}$ Université de Paris, Institute of Psychiatry and Neuroscience of Paris (IPNP), INSERM U1266, F-75014 Paris, France

${ }^{5}$ Section of Eating Disorders, Department of Psychological Medicine, Institute of Psychiatry, Psychology and Neuroscience, King's College London, London, United Kingdom

\section{${ }^{*}$ Corresponding Author}

Laura Di Lodovico

Clinique des Maladies Mentales et de l'Encéphale

Hôpital Sainte-Anne, GHU Paris Psychiatrie et Neurosciences, F-75014 Paris, France

1 Rue Cabanis

Paris, 75014, France

Tel: (+33) 145598572

Fax: (+33) 145658943

E-mail: laura.dilodovico@yahoo.com

Short running Title: Physical exercise endophenotypes in Anorexia Nervosa

Trial registration number: NCT02995226

Word count

- Abstract : 227 words

- Main text : 2559 words 


\section{Statements}

\section{Data availability statement}

The data that support the findings of this study are available from the corresponding author, upon reasonable request.

\section{Acknowledgements}

Laura Di Lodovico and Hanna Hatteea equally contributed to the realization of this paper.

\section{Statement of ethics}

The authors assert that all procedures contributing to this work comply with the ethical standards of the relevant national and institutional committees on human experimentation and with the Helsinki Declaration of 1975, as revised in 2008. This protocol was approved by the Île-de-France III Ethics Committee and the CNIL (Commission Nationale de I'Informatique et des Libertés). Written informed consent was obtained from each participant before inclusion.

\section{Disclosure statement}

The authors have no conflicts of interest to declare.

\section{Funding sources}

This study received a grant research from the "Fondation de l'Avenir" [Grant number: APRMA-16-040]. Janet Treasure acknowledges financial support from the National Institute for Health Research (NIHR) Specialist Biomedical Research Centre for Mental Health award to the South London and Maudsley NHS Foundation Trust and the Institute of Psychiatry, King's College London.

\section{Author contributions}

Laura Di Lodovico: original draft preparation, writing and editing, visualization, formal analysis, investigation, data curation.

Hanna Hatteea: conceptualization, methodology, investigation, data curation.

Céline Couton : investigation, data curation.

Philibert Duriez: investigation and supervision.

Janet Treasure: review and editing.

Philip Gorwood: conceptualization, methodology, project administration, supervision, formal analysis, resources, funding acquisition, review and editing. 


\section{Abstract}

\section{BACKGROUND}

The persistence of physical exercise in Anorexia Nervosa (AN) despite underweight and its maintaining factors are poorly understood. The aim of this study was to explore the attitudes towards physical exercise and its effects on emotions, cognitive functioning and body image perception in patients with $\mathrm{AN}$, and to search for exercise-related endophenotypes of the pathology.

\section{METHODS}

Physical exercise dependence, quantity and dysregulation were assessed by the Exercise Dependence Scale (EDS), the Godin Leisure Time Exercise Questionnaire (GLTEQ) and a standardized effort test in 88 patients with AN, 30 unaffected relatives and 89 healthy controls. Changes in positive and negative affect, cognitive rigidity, and body image distortion were measured before and after the effort test in the three groups.

\section{RESULTS}

Patients with AN had higher scores on the EDS and the GLTEQ and used more effort in the standardized effort test. These three measures of physical exercise correlated with negative emotions at baseline. After the effort test, patients with AN had marked emotional improvement, a moderate increase in body image distortion and a small increase in cognitive rigidity compared to $\mathrm{HC}$. Unaffected relatives also had a significant post-exercise increase of positive emotion.

\section{CONCLUSIONS}

The mood-related drive for physical exercise has the characteristics of an endophenotype of the disorder. Excessive and driven physical exercise may be stateassociated features of AN, driven by the positive effect on emotional wellbeing.

Keywords: Anorexia Nervosa, Physical Exercise, Endophenotype, Emotions, Body Image. 
Anorexia Nervosa (AN) is characterized by persistent restriction of energy intake leading to significantly low body weight, a fear of becoming fat and a distortion of body image (American Psychiatric Association, 2013). Besides food restriction, starvation and purging behaviours, strategies to control weight and shape encompass an excessive and inappropriate practice of physical exercise (Dalle Grave, Calugi, \& Marchesini, 2008; Meyer, Taranis, Goodwin, \& Haycraft, 2011; Rizk et al., 2015).

A paradoxical increase in motor activity, in the context of the frailty associated with illness progression, has been found in up to $85 \%$ of patients with AN (Rizk et al., 2015; Sauchelli et al., 2015; Stiles-Shields, Bamford, Lock, \& Le Grange, 2015). The unique character of this persistent drive to physical exercise leads to the hypothesis that driven (i.e. intense and compulsive) exercise constitutes an endophenotype of the disorder (Casper, 2016; Stiles-Shields et al., 2011). This hypothesis is further supported by the fact that the polygenic risk score (PRS) of anorexia nervosa significantly correlates $\left(r=0.17 ; p=10^{-4}\right)$ with the PRS of physical activity (Watson et al., 2019).

The mechanism underpinning the maintenance of excessive physical exercise at advanced stages of AN is unknown. One hypothesis is that the mood regulating and anxiolytic properties of physical exercise may be involved (Dishman, 1985; Gümmer et al., 2015; Keyes et al., 2015). Other explanatory factors include enhanced cognitive rigidity (Di Lodovico \& Gorwood, 2019) leading to highly stereotyped exercise routines, obsessive-compulsiveness (Halmi et al., 2005; Shroff et al., 2006) and an alteration of the reward system towards exercise and food restriction (Giel et al., 2013; O'Hara, Campbell, \& Schmidt, 2015). These findings are integrated into the cognitive-behavioural model proposed by Meyer et al. (Meyer et al., 2011). In this model mood dysregulation, cognitive rigidity and distortion of body image are involved in a vicious circle whereby physical exercise is used as a strategy to cope with negative emotions and negative body perceptions.

The persistence of high motivation to exercise after weight restoration suggests that the tendency towards excessive physical exercise might be a state-independent, clinical feature of AN pathology (Klein et al., 2010; Shroff et al., 2006). The possible familial, endophenotype nature of this trait has not been studied. Endophenotypes are primarily state-independent, heritable subclinical traits associated with illness in the population, tending to co-segregate with illness within families and thus found in nonaffected family members at higher rates than in the general population (Gottesman \& Gould, 2003). 
In the present study, the hypotheses tested were that patients with AN would

show (1) higher levels of excessive and driven physical exercise compared with healthy controls, that (2) physical effort would increase positive emotions, and be associated with changes in cognitive rigidity and body image distortion (3), and that these effects have endophenotypic characteristics, i.e. are greater in unaffected relatives of patients with AN than in healthy controls.

\section{Materials and Methods}

\section{Participants}

The present study utilizes data collected as part of a monocentric open trial (NCT02995226). Consecutively admitted patients with AN, first-degree unaffected relatives (UR) and healthy controls $(\mathrm{HC})$ were offered the opportunity to participate in this study. In total, 207 participants were included in three groups by parallel assignment: 1) AN (n=88, including 68 inpatients and 20 outpatients), 2) UR ( $n=30)$, all unrelated to the patients included, and 3) $\mathrm{HC}(\mathrm{n}=89)$.

Inclusion criteria for the AN group were: female sex, age between 18 - 50 years, Body Mass Index (BMI) between 14 and $17.5 \mathrm{~kg} / \mathrm{m}^{2}$, and diagnosis of AN according to the DSM-5 criteria (American Psychiatric Association, 2013). The Eating Disorder Inventory-2 and the MINI (Mini-International Neuropsychiatric Interview) 6.0.0 for DSM-IV (Sheehan et al., 1998) were performed by trained psychologists or psychiatrists.

Inclusion criteria for UR and HC were: female sex, age between 18 - 50 years, $\mathrm{BMI}>17.5 \mathrm{~kg} / \mathrm{m}^{2}$, and no personal history of eating disorder.

Exclusion criteria for all groups were: contraindications to the practice of an intensive sport, personal history of stroke, phlebitis, hypertension and/or heart attack, surgical, musculoskeletal, osteoarticular and/or neurological pathology, a first degree family history of stroke at the age of $<45$ years, a first degree familial history of heart attack and/or sudden death at the age of $<55$ years, and the existence of severe psychiatric diagnoses screened by the MINI (lifetime and/or current mood and/or psychotic disorders).

Personal history and/or a current diagnosis of eating disorders according to the $\mathrm{MINI}$ and/or the EDI-2 represented an exclusion criterion for the UR and HC groups.

All study procedures were approved by the Île-de-France III Ethics Committee and the Commission Nationale de I'Informatique et des Libertés. In accordance with the 
Helsinki declaration, written informed consent was obtained from each participant before inclusion.

\section{Instruments}

Eating Disorder Inventory-2 (EDI-2). The EDI-2 (Criquillon-Doublet, Divac, Gaillac, Dardennes, \& Guelfi, 1995; Garner, 1991) explores attitudinal and behavioural dimensions relevant to eating disorders. Internal consistency is $>.80$ in patients with AN for the eight EDI original scales (Garner, Olmstead, \& Polivy, 1983), .65 to .75 for the three additional scales (Eberenz \& Gleaves, 1994), and >.60 in HC (Garner et al., 1983).

Exercise Dependence Scale-R (EDS-R). The EDS-R (Downs, Hausenblas, \& Nigg, 2004) is a 21-item assessment of symptoms of exercise dependence based on the DSM-IV criteria for substance dependence. Higher scores indicate more symptoms of exercise dependence (Hausenblas \& Downs, 2002). The French version of the EDS-R preserves the structural validity of the original scale and shows acceptable internal consistency, with Cronbach's alphas ranging from .75 to .89 (Kern, 2007).

Godin Leisure Time Exercise Questionnaire (GLTEQ). The GLTEQ (Godin \& Shephard, 1997) allows a quantitative estimate of the average physical exercise practised over a 7-day period (Amireault \& Godin, 2015). To ensure the interpretability of the GLTEQ for inpatients with AN, the latter were asked to rate the amount of physical exercise performed during the week preceding the admission the unit.

Standardized effort test. A standardized effort test was performed by each participant on a bicycle connected to a computer by a TACX hometrainer® software. The standardized effort test is designed to obtain the same load of effort from each participant. During the standardized effort test, heart rate, power (watts), and speed $(\mathrm{km} / \mathrm{h})$ were recorded every 30 seconds. There were three phases in this test (Figure 1). In the "spontaneous effort" phase, participants were asked to ride for 1 kilometre at the speed they would subjectively feel as "pleasurable". Next, in the "maximum effort phase", the power of the device automatically rose 30 watts every 2 minutes until the workload became unbearable: the power of the last segment completed corresponded to the maximum aerobic power (MAP). The "imposed effort phase" was a 15-minute ride at $50 \%$ of the MAP reached in the second phase. The "effort dysregulation index" was calculated as the percentage of MAP delivered during the "spontaneous effort" phase (figure 1). The higher this percentage, the smaller the subjective difference between "pleasurable" and "maximum" effort, i.e. pleasure linked to physical effort. Baseline glycaemia and time after the last meal were also recorded as potential confounding factors (Kennedy \& Scholey, 2000). 
Wisconsin Card Sorting Test (WCST). The WCST (Heaton, Chelune, Talley, Kay, \& Curtiss, 1993) entails matching presented cards with one of four multidimensional category cards according to implicit, changing rules (Tchanturia et al., 2012). The proxy measure of cognitive rigidity was the percentage of perseverative errors. In order to limit the learning effect the 64-item-version (Kongs, Thompson, Iverson, \& Heaton, 2000) was split in half to measure performance before and after the effort test.

Body image distortion assessment. Patients were invited to choose the silhouette that most closely represented their perceived body image among ten female silhouettes, each corresponding to a specific BMI (Mouchès, 1992). Body image distortion was calculated as the difference between the BMI of the silhouette chosen and real BMI (Sala et al., 2012). The order of the images was randomised before and after the exercise to avoid a practice effect.

Positive and Negative Affect Schedule (PANAS). The 10-item version of the PANAS validated in French (Gaudreau, Sanchez, \& Blondin, 2006) assesses momentary positive and negative affect on a 5-point Likert scale from "not at all" to "extremely". The two scales show a good internal consistency with a Cronbach's alpha $>.90$ for positive scale and $>.80$ for negative items (Gaudreau et al., 2006). The correlation between the two scales is invariably low (-.15) (Watson, Clark, \& Tellegen, 1988).

\section{Statistical analysis}

All data were preliminarily assessed for parametric distribution by the KolmogorovSmirnov test.

Student tests for independent samples were employed for inter-group comparisons, in order to assess differences between patients with $\mathrm{AN}$ and $\mathrm{HC}$ and between $\mathrm{HC}$ and UR in the three measures of physical exercise and in the effects on the variables assessed before and after the standardized effort test. To fulfil the criteria for an endophenotype, a variable should be associated with target illness, and be more common in UR than in HC (Gottesman \& Gould, 2003) with an effect size of at least $50 \%$ of that of the difference between AN and HC (lacono, Malone, \& Vrieze, 2017).

Bivariate correlation analyses were employed separately in the $A N, H C$ and UR groups to assess the relationships between physical exercise measures and emotional state (PANAS), body image distortion and perseverative errors as an index of rigidity (WCST).

An analysis of covariance (ANCOVA) was run to rule out the influence of potentially confounding, uncontrolled variables on the differences found in the variables of interest 
between UR and $\mathrm{HC}$, in order to confirm their endophenotypic nature.

All tests were performed using SPSS (IBM Corp. Released 2012. IBM SPSS Statistics for Macintosh, Version 21.0. Armonk, NY: IBM Corp).

\section{Results}

\section{Group characteristics}

Patients with AN were similar in age to HC. UR were older since mothers were included. AN and UR groups had higher body image distortion and lower positive emotions than $\mathrm{HC}$ at baseline (table 1).

\section{Characteristics of physical exercise}

Patients with AN had higher amounts of weekly exercise, exercise dependence and effort dysregulation indexes than HC. Effect sizes by Cohen's $d$ are shown in table 1 . The amounts of weekly exercise in AN inpatients (prior to admission) and outpatients were comparable $(51.53 \pm 31.41$ vs $54.90 \pm 28.62 \mathrm{METs}, t=.43 ; \mathrm{df}=86 ; p=.67 ; d=.11)$.

UR had lower exercise levels and dependence, but higher, non-significant $(\mathrm{d}=.13)$ effort dysregulation indexes than $\mathrm{HC}$ (table 1).

The relationship between physical exercise and emotions, cognitive rigidity and body image distortion

In patients with $\mathrm{AN}$, following the experimental effort test, there was a large increase of positive emotions, moderate increases of body image distortion and decreases of negative emotions, and small increase of cognitive rigidity, when compared to HC. See table 1 for effect sizes. Post-exercise increases of positive emotion and body image distortion were uncorrelated $(r=.15 ; p=.18)$.

In UR, following the effort test, there was a significant increase of positive emotions compared to $\mathrm{HC}$, with an effect size larger than $50 \%$ of that of the difference between $\mathrm{AN}$ and $\mathrm{HC}$ (table 1). This remained higher after controlling for age and time from last meal $(F(1,117)=6.89 ; p=.01)$.

In patients with $\mathrm{AN}$, negative emotions at baseline were significantly correlated with the three measures of physical exercise, and these correlations did not lose statistical significance when the analyses were repeated after excluding the 10 patients diagnosed with depression $(r=.27 ; p=.02$ for the EDS, $r=.31 ; p<.01$ for the GLTEQ and $r=.23 ; p=.04$ for the effort dysregulation index). Body image distortion was positively correlated with the amount of exercise practiced (all correlations are reported in table 2). 
In UR, only a positive correlation between body image distortion and the EDS score was found.

\section{Discussion}

This study explored the nature of physical exercise in AN, and its relationship with positive and negative emotions, cognitive rigidity and body image distortion. We also explored the familial nature of this relationship to examine for potential endophenotypes.

A tendency to excessive and driven exercise significantly distinguished patients with $\mathrm{AN}$ from $\mathrm{HC}$. A strong relationship was found between negative emotions and a more intensive frequency, dependence and dysregulation of physical exercise in $A N$, suggesting a possible "anti-depressive" drive of physical exercise. This finding was further confirmed by a significant increase of positive emotions after a single bout of exercise in patients but also in UR, fulfilling the criteria of an endophenotype (Gottesman \& Gould, 2003). Body image distortion was increased after exercise in patients with AN only, supporting a state-related relationship between body image distortion and physical exercise in AN.

The finding of more pronounced amounts and drive for physical exercise in AN is in line with the literature. High amounts of exercise (Bratland-Sanda et al., 2009), higher levels of exercise dependence (Di Lodovico \& Gorwood, 2019), and a stronger willingness to work for the opportunity to exercise (Klein et al., 2010) could be explained by a tendency for AN patients to perceive exercise-related stimuli as more rewarding and pleasant (Giel et al., 2013; Kullmann et al., 2014).

In previous research, negative affect regulation was presented as the main reason for exercise in patients with AN (Bratland-Sanda et al., 2009), higher levels of negative emotions were described in patients who exercise excessively (Shroff et al., 2006), and physical exercise abuse was identified as a predictor of emotional instability in AN (Selby et al., 2015). Our results demonstrate that the positive emotional consequence of physical exercise in $A N$ has the features of an endophenotype. This positive reinforcement (Klein et al., 2010; Walsh, 2013) may lead to the addictive properties of physical exercise in AN (Karr et al., 2017; Klein et al., 2004).

Although positive emotion improved after exercise, body image perception worsened, probably because of abnormal interoception in AN (Jacquemot \& Park, 2020). Taken together, the two divergent perceptions of feeling better because of positive emotions and having greater body image distortion might explain the vicious circle that maintains the drive for exercise in patients with AN (Dalle Grave et al., 2008; Hagman et al., 2015). 
Several limitations are present in this study. The drive to exercise was not compared 293 in patients with restricting type vs bingeing-purging type, nor in inpatients vs outpatients. 294 Nevertheless, previous studies found comparable attitudes towards exercise between 295 these subgroups (Di Lodovico \& Gorwood, 2019; Keyes et al., 2015). This research lacks 296 an assessment of anxious and depressive symptomatology, as subclinical depressive 297 elements could have influenced the PANAS at baseline. Nevertheless, this chance was 298 limited by screening mood disorders and repeating the analyses after excluding the ten 299 patients diagnosed with depression. Potential confounders such as the smaller size and 300 older age of the UR group may have influenced some exercise-related findings. To 301 address this limitation, we controlled those that were statistically different between 302 groups (such as age and time from last meal) in an analysis of covariance, and we 303 analysed all physical efforts parameters according to each participant baseline MAP, 304 therefore controlling for its variability.

305 The main strengths of this study are the use of an experimental approach, testing a 306 direct effect of physical exercise on the main factors involved in its onset and 307 maintenance, and the assessment of these same effects in UR, exploring for the first 308 time exercise-related endophenotypes in AN.

\section{Conclusion}

310 The mood-enhancing effect of physical exercise could represent an endophenotype 311 of AN, suggesting how and why exercise becomes a dominant form of mood regulation. 312 However, the increased body image distortion following exercise may allow this 313 behaviour to become compulsive. Alternative mood-regulating strategies may be needed 314 to break this vicious circle. 


\section{References}

\section{References}

American Psychiatric Association. (2013). Diagnostic and statistical manual of mental disorders (5th ed.). Arlington, VA: American Psychiatric Publishing.

Amireault, S., \& Godin, G. (2015). The Godin-Shephard leisure-time physical activity questionnaire: Validity evidence supporting its use for classifying healthy adults into active and insufficiently active categories. Perceptual and Motor Skills, 120(2), 604622. https://doi.org/10.2466/03.27.PMS.120v19x7

Bratland-Sanda, S., Sundgot-Borgen, J., Rø, O., Rosenvinge, J. H., Hoffart, A., \& Martinsen, E. W. (2010). "I'm not physically active - I only go for walks": Physical activity in patients with longstanding eating disorders. The International journal of eating disorders, 43(1), 88-92. https://doi.org/10.1002/eat.20753

Casper R. C. (2016). Restless activation and drive for activity in anorexia nervosa may reflect a disorder of energy homeostasis. The International journal of eating disorders, 49(8), 750-752. https://doi.org/10.1002/eat.22575

Casper R. C. (2018). Not the function of eating, but spontaneous activity and energy expenditure, reflected in "restlessness" and a "drive for activity" appear to be dysregulated in anorexia nervosa: Treatment implications. Frontiers in psychology, 9 , 2303. https://doi.org/10.3389/fpsyg.2018.02303

Criquillon-Doublet, S., Divac, S., Dardennes, R., \& Guelfi, J.D. (1995). Le "Eating disorder inventory" (EDI). In J.D. Guelfi, V. Gaillac \& R. Dardennes (Eds.), Psychopathologie quantitative (pp. 249-260). Paris, France: Masson.

Dalle Grave, R., Calugi, S., \& Marchesini, G. (2008). Compulsive exercise to control shape or weight in eating disorders: Prevalence, associated features, and treatment outcome. Comprehensive Psychiatry, 49(4), 346-352. https://doi.org/10.1016/j.comppsych.2007.12.007 
Di Lodovico, L., Dubertret, C., \& Ameller, A. (2018). Vulnerability to exercise addiction, sociodemographic, behavioral and psychological characteristics of runners at risk for eating disorders. Comprehensive Psychiatry, 81, 48-52. https://doi.org/10.1016/j.comppsych.2017.11.006

Di Lodovico, L., \& Gorwood, P. (2019). The relationship between moderate to vigorous physical activity and cognitive rigidity in anorexia nervosa. Psychiatry Research, 284, 112703. https://doi.org/10.1016/j.psychres.2019.112703

Dishman, R. K. (1985). Medical psychology in exercise and sport. Medical Clinics of North America, 69(1), 123-143. https://doi.org/10.1016/S0025-7125(16)31061-6

Downs, D. S., Hausenblas, H. A., \& Nigg, C. R. (2004). Factorial validity and psychometric examination of the exercise dependence scale-revised. Measurement in Physical Education and Exercise Science, 8(4), 183-201. https://doi.org/10.1207/s15327841mpee0804_1

Eberenz, K. P., \& Gleaves, D. H. (1994). An examination of the internal consistency and factor structure of the eating disorder inventory-2 in a clinical sample. The International Journal of Eating Disorders, 16(4), 371-379. https://doi.org/10.1002/1098-108x(199412)16:4<371::aid-eat2260160406>3.0.co;2-w

Engel, S. G., Wonderlich, S. A., Crosby, R. D., Mitchell, J. E., Crow, S., Peterson, C. B. ... Gordon, K. H. (2013). The role of affect in the maintenance of anorexia nervosa: Evidence from a naturalistic assessment of momentary behaviors and emotion. Journal of Abnormal Psychology, 122(3), 709-719. https://doi.org/10.1037/a0034010

Garner, D, Olmstead, M., \& Polivy, J. (1983). Development and validation of a multidimensional eating disorder inventory for anorexia nervosa and bulimia. International Journal of Eating Disorders, 2(2), 15-34.

Garner, D. M. (1991). Eating disorder inventory-2: Professional manual. Odessa, FL: Psychological Assessment Resources.

Gaudreau, P., Sanchez, X., \& Blondin, J.-P. (2006). Positive and negative affective states in a performance-related setting: Testing the factorial structure of the PANAS across 
two samples of French-Canadian participants. European Journal of Psychological Assessment, 22(4), 240-249. https://doi.org/10.1027/1015-5759.22.4.240

Giel, K. E., Kullmann, S., PreißI, H., Bischoff, S. C., Thiel, A., Schmidt, U., ... Teufel, M. (2013). Understanding the reward system functioning in anorexia nervosa: Crucial role of physical activity. Biological Psychology, 94(3), 575-581. https://doi.org/10.1016/j.biopsycho.2013.10.004

Godin, G., \& Shepherd, R.J. (1997). Godin leisure-time exercise questionnaire. Medicine and Science in Sports and Exercise, 26(Suppl. 6), S36-S38.

Gorwood, P., Blanchet-Collet, C., Chartrel, N., Duclos, J., Dechelotte, P., Hanachi, M., ... Epelbaum, J. (2016). New insights in anorexia nervosa. Frontiers in Neuroscience, 10, 1-21. https://doi.org/10.3389/fnins.2016.00256

Gottesman, I. I., \& Gould, T. D. (2003). The endophenotype concept in psychiatry: etymology and strategic intentions. American Journal of Psychiatry, 160(4), 636-645. https://doi.org/10.1176/appi.ajp.160.4.636

Gümmer, R., Giel, K. E., Schag, K., Resmark, G., Junne, F. P., Becker, S., ... Teufel, M. (2015). High levels of physical activity in anorexia nervosa: A systematic review. European Eating Disorders Review, 23(5), 333-344. https://doi.org/10.1002/erv.2377

Hagman, J., Gardner, R. M., Brown, D. L., Gralla, J., Fier, J. M., \& Frank, G. K. (2015). Body size overestimation and its association with body mass index, body dissatisfaction, and drive for thinness in anorexia nervosa. Eating and weight disorders, 20(4), 449455. https://doi.org/10.1007/s40519-015-0193-0

Halmi, K. A., Tozzi, F., Thornton, L. M., Crow, S., Fichter, M. M., Kaplan, A. S., ... Bulik, C. M. (2005). The relation among perfectionism, obsessive-compulsive personality disorder and obsessive-compulsive disorder in individuals with eating disorders. International Journal of Eating Disorders, 38(4), 371-374. https://doi.org/10.1002/eat.20190 
Hausenblas, H. A., \& Downs, D. S. (2002). How much is too much? The development and validation of the exercise dependence scale. Psychology \& Health, 17(4), 387-404. https://doi.org/10.1080/0887044022000004894

Heaton, R. K., Chelune, G. J., Talley, J. L., Kay, G. G., \& Curtiss, G. (1993). Wisconsin card sorting test manual: revised and expanded. Odessa, FL: Psychological Assessment Resources.

lacono, W. G., Malone, S. M., \& Vrieze, S. I. (2017). Endophenotype best practices. International journal of psychophysiology, 111, 115-144. https://doi.org/10.1016/j.ijpsycho.2016.07.516

Jacquemot, A., \& Park, R. (2020). The role of interoception in the pathogenesis and treatment of anorexia nervosa: A narrative review. Frontiers in psychiatry, 11, 281. https://doi.org/10.3389/fpsyt.2020.00281

Karr, T., Cook, B., Zuncker, C., Cao, L., Crosby, L., Wonderlitch, G., \& Mitchell, J. (2017). Examining physical activity and affect using objective measures: A pilot study of anorexia nervosa. The Sport Journal.

Retrieved from https://thesportjournal.org/article/examining-physical-activity-andaffect-using-objective-measures-a-pilot-study-of-anorexia-nervosa/

Kennedy, D. O., \& Scholey, A. B. (2000). Glucose administration, heart rate and cognitive performance: Effects of increasing mental effort. Psychopharmacology, 149(1), 6371. https://doi.org/10.1007/s002139900335

Kern, L. (2007). Validation de l'adaptation française de l'échelle de dépendance à l'exercice physique: L'EDS-R. Pratiques Psychologiques, 13(4), 425-441.

https://doi.org/10.1016/j.prps.2007.06.003

Keyes, A., Woerwag-Mehta, S., Bartholdy, S., Koskina, A., Middleton, B., Connan, F., ... Campbell, I. C. (2015). Physical activity and the drive to exercise in anorexia nervosa. International Journal of Eating Disorders, 48(1), 46-54. https://doi.org/10.1002/eat.22354 
Klein, D. A., Bennett, A. S., Schebendach, J., Foltin, R. W., Devlin, M. J., \& Walsh, B. T. (2004). Exercise "addiction" in anorexia nervosa: Model development and pilot data. CNS Spectrums, 9(7), 531-537. https://doi.org/10.1017/s1092852900009627

Klein, D. A., Schebendach, J. E., Gershkovich, M., Bodell, L. P., Foltin, R. W., \& Walsh, B. T. (2010). Behavioral assessment of the reinforcing effect of exercise in women with anorexia nervosa: Further paradigm development and data. International Journal of Eating Disorders, 43(7), 611-618. https://doi.org/10.1002/eat.20758

Kongs, K., Thompson, L., Iverson, G., \& Heaton, R. (2000). Wisconsin card sorting test-64 card version (WCST-64). Odessa, FL: Psychological Assessment Resources.

Kullmann, S., Giel, K. E., Hu, X., Bischoff, S. C., Teufel, M., Thiel, A., ... Preissl, H. (2014). Impaired inhibitory control in anorexia nervosa elicited by physical activity stimuli. Social Cognitive and Affective Neuroscience, 9(7), 917-923. https://doi.org/10.1093/scan/nst070

Meyer, C., Taranis, L., Goodwin, H., \& Haycraft, E. (2011). Compulsive exercise and eating disorders. European Eating Disorders Review, 19(3), 174-189. https://doi.org/10.1002/erv.1122

Mouchès, A. (1992). Erreurs perceptives de l'image corporelle, troubles émotionnels et comportement alimentaire. Journal de Thérapie Comportementale et Cognitive, 2(3), 8-14.

O'Hara, C. B., Campbell, I. C., \& Schmidt, U. (2015). A reward-centred model of anorexia nervosa: A focussed narrative review of the neurological and psychophysiological literature. Neuroscience \& Biobehavioral Reviews, 52, 131-152. https://doi.org/10.1016/j.neubiorev.2015.02.012

Rizk, M., Lalanne, C., Berthoz, S., Kern, L., EVHAN Group, \& Godart, N. (2015). Problematic exercise in anorexia nervosa: Testing potential risk factors against different $\begin{array}{llll}\text { definitions. } & \text { One, } & \text { 10(11), } & \text { 0143352. }\end{array}$ https://doi.org/10.1371/journal.pone.0143352 
Sala, L., Mirabel-Sarron, C., Pham-Scottez, A., Blanchet, A., Rouillon, F., \& Gorwood, P. (2012). Body dissatisfaction is improved but the ideal silhouette is unchanged during weight recovery in anorexia nervosa female inpatients. Eating and Weight Disorders, 17(2), e109-e115. https://doi.org/10.1007/BF03325334

Sauchelli, S., Arcelus, J., Sánchez, I., Riesco, N., Jiménez-Murcia, S., Granero, R., ... Fernandez-Aranda, F. (2015). Physical activity in anorexia nervosa: How relevant is it to therapy response? European Psychiatry, 30(8), 924-931. https://doi.org/10.1016/j.eurpsy.2015.09.008

Selby, E. A., Cornelius, T., Fehling, K. B., Kranzler, A., Panza, E. A., Lavender, J. M., ... Grange, D. L. (2015). A perfect storm: Examining the synergistic effects of negative and positive emotional instability on promoting weight loss activities in anorexia nervosa. Frontiers in Psychology, 6, 1260. https://doi.org/10.3389/fpsyg.2015.01260

Sheehan, D. V., Lecrubier, Y., Sheehan, K. H., Amorim, P., Janavs, J., Weiller, E., ... Dunbar, G. C. (1998). The MINI-international neuropsychiatric interview (MINI): The development and validation of a structured diagnostic psychiatric interview for DSMIV and ICD-10. The Journal of Clinical Psychiatry, 59(Suppl. 20), 22-33. Retrieved from https://www.psychiatrist.com/jcp/neurologic/neurology/mini-internationalneuropsychiatric-interview-mini/

Shroff, H., Reba, L., Thornton, L. M., Tozzi, F., Klump, K. L., Berrettini, W. H., ... Bulik, C. M. (2006). Features associated with excessive exercise in women with eating disorders. International Journal of Eating Disorders, 39(6), 454-461. https://doi.org/10.1002/eat.20247

Stiles-Shields, E. C., Goldschmidt, A. B., Boepple, L., Glunz, C., \& Le Grange, D. (2011). Driven exercise among treatment-seeking youth with eating disorders. Eating behaviors, 12(4), 328-331. https://doi.org/10.1016/j.eatbeh.2011.09.002

Stiles-Shields, C., Lock, J., \& Le Grange, D. (2015). The effect of driven exercise on treatment outcomes for adolescents with anorexia and bulimia nervosa. International Journal of Eating Disorders, 48(4), 392- 396. https://doi.org/10.1002/eat.22281 
Tchanturia, K., Davies, H., Roberts, M., Harrison, A., Nakazato, M., Schmidt, U., ... Morris, R. (2012). Poor cognitive flexibility in eating disorders: Examining the evidence using the Wisconsin card sorting task. PLoS One, 7(1), e28331. https://doi.org/10.1371/journal.pone.0028331

Walsh, B. T. (2013). The enigmatic persistence of anorexia nervosa. American Journal of Psychiatry, 170(5), 477-484. https://doi.org/10.1176/appi.ajp.2012.12081074

Watson, D., Clark, L. A., \& Tellegen, A. (1988). Development and validation of brief measures of positive and negative affect: The PANAS scales. Journal of Personality and Social Psychology, 54(6), 1063-1070. https://doi.org/10.1037/0022$\underline{3514.54 .6 .1063}$

Watson, H. J., Yilmaz, Z., Thornton, L. M., Hubel, C., Coleman, J. R. I., Gaspar, H. A. ... Bulik, C.M. (2019). Genome-wide association study identifies eight risk loci and implicates metabo-psychiatric origins for anorexia nervosa. Nature Genetics, 51(8), 1207- 1214. https://doi.org/10.1038/s41588-019-0439-2 


\section{Figure Legends}

Fig. 1. Design of the study testing positive and negative emotions, cognitive flexibility and body image distortion in patients with anorexia nervosa (AN), healthy controls (HC) and unaffected relatives (UR), at baseline (before exercise) and after a bout of physical exercise (after physical effort).

\section{Table Legends}

Table 1. Inter-group comparison at baseline, during and after a standardized effort test, of 88 patients with anorexia nervosa (AN), 30 unaffected relatives (UR) and 89 healthy controls $(\mathrm{HC})$.

Table 2. Bivariate correlations between physical exercise measures and emotional status, body image perception and cognitive rigidity in a group of 88 patients with Anorexia Nervosa (AN), 30 Unaffected Relatives (UR) and 89 Healthy Controls (HC). Correlations were calculated separately for each group. Asterisks indicate statistically significant correlations. 
Figure 1

Before physical effort

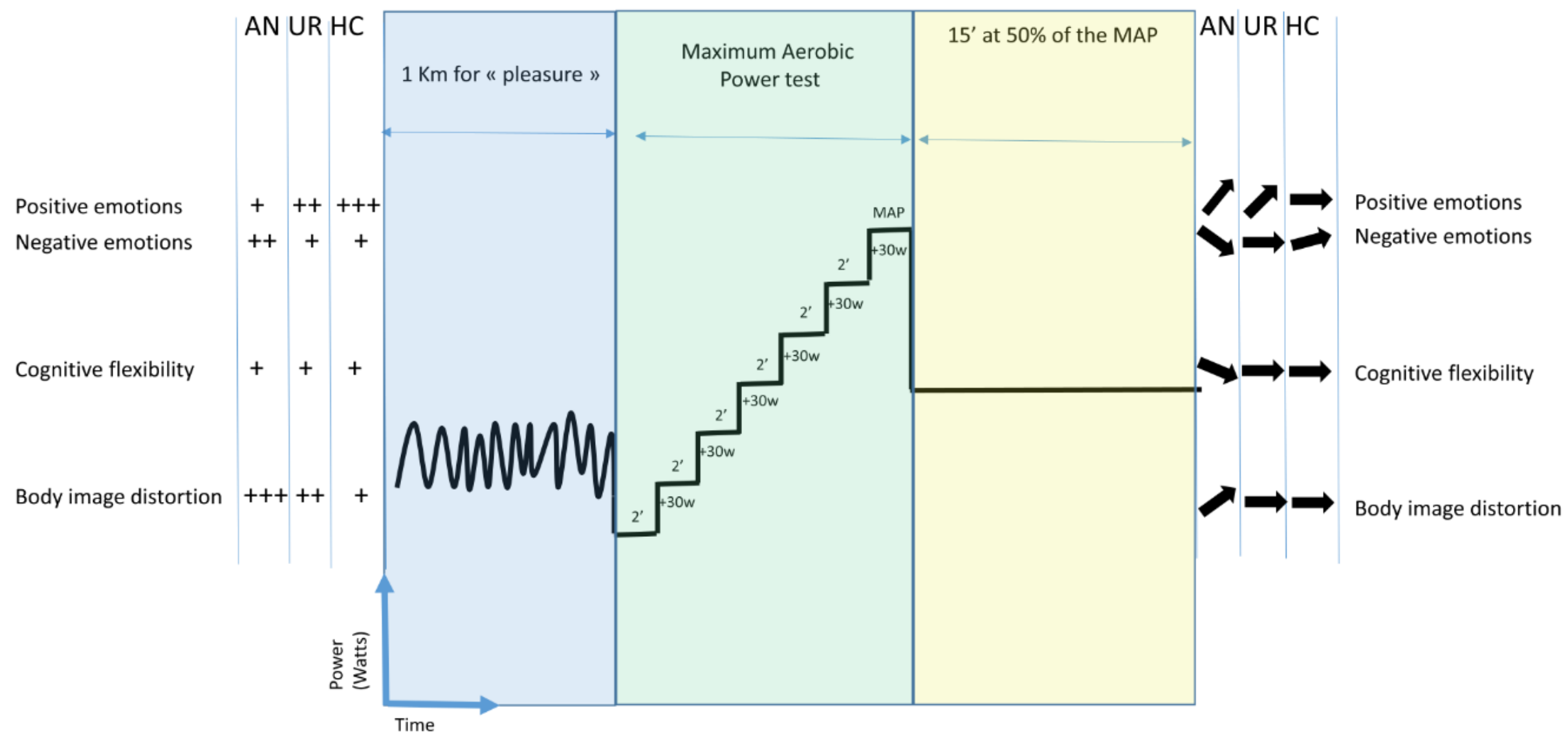

AN: Anorexia Nervosa, UR: Unaffected first-degree Relatives, HC: Healthy Controls 
Table 1: Inter-group comparison at baseline, during and after a standardized effort test, of 88 patients with anorexia nervosa (AN), 30 unaffected relatives (UR) and 89 healthy controls (HC).

\begin{tabular}{|c|c|c|c|c|c|c|c|c|c|c|c|c|c|c|c|}
\hline & \multirow[t]{2}{*}{ AN $(n=88)$} & \multirow[t]{2}{*}{ UR $(n=30)$} & \multirow[t]{2}{*}{$\mathrm{HC}(\mathrm{n}=89)$} & \multicolumn{3}{|c|}{ AN vs UR } & \multirow[b]{2}{*}{ Cohen's d } & \multicolumn{3}{|c|}{ AN vs HC } & \multicolumn{5}{|c|}{ HC vs UR } \\
\hline & & & & $\mathrm{t}$ & DF & $\mathrm{p}$ & & $\mathrm{t}$ & DF & $\mathrm{p}$ & Cohen's d & $\mathrm{t}$ & DF & $\mathrm{p}$ & Cohen's d \\
\hline \multicolumn{16}{|c|}{ Baseline characteristics and performances } \\
\hline Age (years) & $26.83 \pm 7.57$ & $34.53 \pm 11.85$ & $27.46 \pm 5.93$ & -3.33 & 116 & $<.01$ & 0.87 & .62 & 175 & .54 & 0.09 & -3.13 & 117 & $<.01$ & 0.90 \\
\hline BMI (kg/m²) & $16.17 \pm .99$ & $21.64 \pm 2.10$ & $21.82 \pm 2.34$ & -13.75 & 116 & $<.01$ & 4.03 & 15.72 & 175 & $<.01$ & 2.35 & .34 & 117 & .73 & 0.06 \\
\hline Baseline glycaemia (g/l) & $.98 \pm .21$ & $.96 \pm .10$ & $.95 \pm .15$ & .44 & 116 & .66 & 0.07 & .87 & 173 & .39 & 0.13 & -.48 & 116 & .62 & 0.09 \\
\hline Time from last meal $(\mathrm{min})$ & $259.39 \pm 838.49$ & $122.83 \pm 6.39$ & $167.43 \pm 164.69$ & 1.52 & 115 & .13 & 0.19 & 1.00 & 174 & .32 & 0.15 & 2.55 & 117 & .01 & 0.31 \\
\hline EDI-2 total score & $91.07 \pm 48.00$ & $21.60 \pm 16.98$ & $25.54 \pm 20.46$ & 11.56 & 115 & $<.01$ & 1.64 & 11.73 & 174 & $<.01$ & 1.78 & 1.04 & 117 & .30 & 0.20 \\
\hline EDS score & $61.16 \pm 27.48$ & $31.73 \pm 8.19$ & $39.52 \pm 18.45$ & 8.95 & 116 & $<.01$ & 0.45 & 6.37 & 175 & $<.01$ & 0.96 & 2.23 & 118 & .03 & 0.45 \\
\hline GLTEQ total score & $52.30 \pm 30.67$ & $28.57 \pm 18.63$ & $44.93 \pm 24.00$ & 5.04 & 116 & $<.01$ & 0.72 & 1.78 & 175 & .04 & 0.27 & 3.85 & 117 & $<.01$ & 0.72 \\
\hline $\begin{array}{l}\text { Baseline PANAS for positive } \\
\text { emotions }\end{array}$ & $10.80 \pm 3.21$ & $13.00 \pm 2.96$ & $14.92 \pm 3.19$ & -3.45 & 116 & $<.01$ & 0.70 & 8.57 & 175 & $<.01$ & 1.29 & 3.01 & 117 & $<.01$ & 0.61 \\
\hline $\begin{array}{l}\text { Baseline PANAS for negative } \\
\text { emotions }\end{array}$ & $13.63 \pm 4.52$ & $8.83 \pm 2.48$ & $8.24 \pm 2.43$ & 7.25 & 116 & $<.01$ & 1.17 & 9.86 & 175 & $<.01$ & 1.49 & -1.15 & 117 & .25 & 0.24 \\
\hline $\begin{array}{l}\text { Baseline WCST number of } \\
\text { perseverative errors }\end{array}$ & $3.13 \pm 2.51$ & $3.07 \pm 4.26$ & $2.78 \pm 2.39$ & .08 & 96 & .93 & 0.02 & .82 & 131 & .41 & 0.38 & .34 & 93 & .73 & 0.09 \\
\hline $\begin{array}{l}\text { Baseline body image distortion } \\
\left(\mathrm{kg} / \mathrm{m}^{2}\right)\end{array}$ & $5.08 \pm 3.23$ & $2.35 \pm 2.32$ & $1.07 \pm 2.93$ & 5.00 & 116 & $<.01$ & 0.90 & 8.66 & 175 & $<.01$ & 1.30 & -2.45 & 117 & .02 & 0.46 \\
\hline \multicolumn{16}{|l|}{ Standardized effort test } \\
\hline Maximum aerobic power (MAP) & $112.27 \pm 34.99$ & $139.00 \pm 29.64$ & $151.00 \pm 32.94$ & -4.07 & 116 & $<.01$ & 0.79 & 8.30 & 175 & $<.01$ & 1.24 & 1.48 & 117 & .14 & 0.56 \\
\hline Spontaneous effort average power & $38.49 \pm 17.96$ & $40.80 \pm 13.17$ & $44.15 \pm 17.41$ & .75 & 116 & .45 & 0.14 & 2.13 & 175 & .03 & 0.32 & 1.10 & 117 & .27 & 0.20 \\
\hline $\begin{array}{l}\text { Effort dysregulation index (average } \\
\text { spontaneous power/MAP) }\end{array}$ & $35.08 \pm 15.38 \%$ & $30.15 \pm 10.22 \%$ & $28.52 \pm 13.05 \%$ & 1.98 & 116 & .05 & 0.34 & 3.05 & 175 & $<.01$ & 0.46 & .70 & 117 & .24 & 0.13 \\
\hline \multicolumn{16}{|c|}{ Changes induced by physical effort } \\
\hline $\begin{array}{l}\text { PANAS positive emotions after- } \\
\text { before effort }\end{array}$ & $2.69 \pm 3.52$ & $1.97 \pm 2.52$ & $.52 \pm 2.65$ & 1.22 & 116 & .22 & 0.55 & 4.65 & 175 & $<.01$ & 0.70 & 2.69 & 117 & $<.01$ & 0.55 \\
\hline $\begin{array}{l}\text { PANAS negative emotions after- } \\
\text { before effort }\end{array}$ & $-.12 \pm 2.88$ & $.20 \pm 2.04$ & $.85 \pm 2.12$ & .67 & 116 & .50 & 0.31 & 2.57 & 175 & .01 & 0.39 & 1.50 & 117 & .14 & 0.31 \\
\hline $\begin{array}{l}\text { WCST number of perseverative } \\
\text { errors after - before effort }\end{array}$ & $.22 \pm 3.36$ & $-.60 \pm 4.10$ & $-0.95 \pm 2.37$ & .96 & 96 & .34 & 0.12 & 2.33 & 130 & .02 & 0.40 & .44 & 93 & .66 & 0.12 \\
\hline $\begin{array}{l}\text { Perceived body image after - } \\
\text { before effort }(\mathrm{kg} / \mathrm{m} 2)\end{array}$ & $.50 \pm 1.54$ & $-.01 \pm 1.22$ & $.12 \pm 1.51$ & 1.82 & 116 & .07 & 0.09 & 1.66 & 174 & .04 & 0.25 & .45 & 117 & .65 & 0.09 \\
\hline
\end{tabular}

AN= Anorexia Nervosa; UR= Unaffected Relatives; HC= Healthy Controls; BMI= Body Mass Index; EDI-2= Eating Disorder Inventory-2; EDS= Exercise Dependence Scale; GLTEQ= Godin Leisure Time Exercise Questionnaire; PANAS= Positive And Negative Affect Schedule; WCST= Wisconsin Card Sorting Test. 
Table 2: Bivariate correlations between physical exercise measures and emotional status, body image perception and cognitive rigidity in a group of 88 patients with Anorexia Nervosa (AN), 30 Unaffected Relatives (UR) and 89 Healthy Controls (HC). Correlations were calculated separately for each group. Asterisks indicate statistically significant correlations.

\begin{tabular}{|c|c|c|c|c|c|c|c|c|c|}
\hline \multirow[b]{2}{*}{ Exercise measures } & \multirow[b]{2}{*}{$n$} & \multicolumn{2}{|c|}{ PANAS baseline positive emotions } & \multicolumn{2}{|c|}{ PANAS baseline negative emotions } & \multicolumn{2}{|c|}{ WCST perseverative errors at baseline } & \multicolumn{2}{|c|}{ Body image distortion at baseline } \\
\hline & & $\mathrm{r}$ & $\mathrm{p}$ & $\mathrm{r}$ & $\mathrm{p}$ & $\mathrm{r}$ & $\mathrm{p}$ & $\mathrm{r}$ & $\mathrm{p}$ \\
\hline \multicolumn{10}{|l|}{ EDS score } \\
\hline AN & 88 & -15 & .15 & $.27 *$ & .01 & .02 & .86 & .08 & .88 \\
\hline UR & 30 & -.20 & .28 & -.01 & .95 & -.10 & .58 & $.04 *$ & .03 \\
\hline HC & 89 & $.29 *$ & $<.01$ & -.04 & .74 & -.04 & .78 & .07 & .52 \\
\hline \multicolumn{10}{|l|}{ GLTEQ score } \\
\hline AN & 88 & -.20 & .06 & $.30^{*}$ & $<.01$ & -.09 & .86 & $.29 *$ & $<.01$ \\
\hline UR & 30 & .11 & .56 & -.07 & .71 & -.27 & .15 & -.25 & .19 \\
\hline $\mathrm{HC}$ & 89 & $.27^{*}$ & .01 & .02 & .83 & .02 & .84 & .15 & .17 \\
\hline \multicolumn{10}{|c|}{ Effort dysregulation index } \\
\hline AN & 88 & -.12 & .25 & $.23^{*}$ & .03 & .02 & .85 & .06 & .56 \\
\hline UR & 30 & -.09 & .63 & .09 & .64 & .29 & .12 & .31 & .09 \\
\hline $\mathrm{HC}$ & 89 & -.05 & .63 & -.05 & .62 & .05 & .67 & $<.01$ & .98 \\
\hline
\end{tabular}

AN= Anorexia Nervosa; UR= Unaffected Relatives; HC= Healthy Controls; PANAS= Positive and Negative Affect Schedule; WCST= Wisconsin Card Sorting Test; EDS= Exercise Dependence Scale; GLTEQ= Godin Leisure Time Exercise Questionnaire. 